\title{
Morphometric Indices and Enteroparasitic Infestation of Clarias gariepinus (Burchell, 1822) in a Tropical Reservoir
}

\author{
Olumuyiwa Olasunmibo Ajala*, Olatunde 0. Fawole \\ Department of Pure and Applied Biology, Ladoke Akintola University of Technology, Ogbomoso, Nigeria \\ Email: *ooajala@lautech.edu.ng
}

How to cite this paper: Ajala, O.O. and Fawole, O.O. (2019) Morphometric Indices and Enteroparasitic Infestation of Clarias gariepinus (Burchell, 1822) in a Tropical Reservoir. Agricultural Sciences, 10, 1286-1297. https://doi.org/10.4236/as.2019.1010095

Received: March 25, 2019

Accepted: September 11, 2019

Published: October 9, 2019

Copyright $\odot 2019$ by author(s) and Scientific Research Publishing Inc. This work is licensed under the Creative Commons Attribution International License (CC BY 4.0).

http://creativecommons.org/licenses/by/4.0/

\section{c) (i) Open Access}

\begin{abstract}
The study was carried out using 328 Clarias gariepinus specimens over a period of two years, from Oba reservoir $\left(08^{\circ} 3^{\prime} \mathrm{N}\right.$ to $08^{\circ} 12^{\prime} \mathrm{N}$ and $004^{\circ} 6^{\prime} \mathrm{E}$ to $\left.004^{\circ} 12^{\prime} \mathrm{E}\right)$ Ogbomoso, Oyo State, Nigeria. Standard methods were used to determine length-weight relationship, condition factor, and enteroparasitic infestation of the fish in the reservoir. Generally, Fish growth was positively allometric, while infested male and female fishes had negative allometric growth. The general well-being of the male fish was better than that of the female fish. Smaller sized fishes were better adapted to the ecological conditions of the reservoir than the bigger fishes. Parasites recovered were two Nematodes (Procamallanus laevionchus, Paracamallanus cyathopharynx), three Cestodes (Anomotaenia sp. Monobothrium sp., Polyonchobothrium clariae), and one Acanthocephalan (Neoechinorhynchus rutili). Sex ratio was 1.3:1 (male: female). Parasitic prevalence and intensity in the fish were sex and season dependent. The effect of enteroparasites in the life of infested $C$. gariepinus was found to probably be a major factor responsible for the low percentage of good fit to the line of regression $\left(\mathrm{R}^{2}\right)$ in females. Infestation also led to loss of weight in infested fishes and this affected morphometric values in which body weight was an index.
\end{abstract}

\section{Keywords}

Allometric, Clarias gariepinus, Enteroparasites, Infestation, Morphometric

\section{Introduction}

Oba reservoir is one of the thirteen reservoirs and lakes in Oyo state Nigeria [1]. It sustains a thriving artisanal fisheries industry and serves as a source of domestic water for the citizens of Ogbomoso North and South local governments. Cla- 
rias gariepinus belongs to family Clariidae, and can survive during the dry season due to the possession of accessory air-breathing organ [2]. The scientific basis for morphometric in fishes, and the mathematical way that weight relates to length, was set by Fulton, in 1906, who for the first time introduced fisheries science into "allometry" [3]. The most commonly used relationships are those relating weight to body length (in the majority of cases, total body length-TL) and different types of lengths (i.e., standard-SL- and fork-FL-lengths) to TL [4]. In Fisheries science, the condition factor is used in order to compare the "condition", "fatness", or well-being of fish. It is based on the hypothesis that heavier fishes of a particular length are in a better physiological condition [5]. It provides information on the well-being of a fish and is usually influenced by the fish, sex, season, maturity stage, etc. [6]. A high condition factor reflects good environmental quality; while a low condition factor reflects poor environmental quality [7].

Parasitic diseases of fish are very common all over the world and are of particular importance in the tropics [8]. C. gariepinus is known to possess one of the richest parasite fauna, which can be attributed to its diet [9]. The following parasites: Procamallanus laevionchus, Paracamallanus cyathopharynx (Nematodes), Anomotaenia sp., Monobothrium sp., Polyonchobothrium clariae (Cestodes) and Neoechinorhynchus rutili (Acanthocephalan) were recovered from the stomach and intestine of $C$. gariepinus from Erinle reservoir [10] and Oba reservoir [11], Southwest of Nigeria. Some parasites have been recorded to have zoonotic potentials in mammalian host including man thereby making them of public health importance. Fish borne zoonotic Trematodes (FZT) are transmitted to humans as metacercariae that have been found encysted in fish. They are an emerging problem and recent global health assessments have identified FZT as among the most important and neglected parasitic zoonotic diseases [12]. Parasitic infestation/infection of fish, hampers their appearance, growth, reproduction, performance, reduces their relative values, palatability, and production [13]. FZT have shown that parasites can use fish as a zoonotic pathway to man, which makes this investigation necessary. This study investigates aspects of morphometric indices and enteroparasitic infestation of $C$. gariepinus and determines how the infestation affects the morphometric values of the fish.

\section{Materials and Method}

The study area was Oba reservoir in Ogbomoso North local government area of Oyo state, Nigeria. The area is characterized by annual dry season months of October to March and raining season months of April to September. The vegetation of the shoreline is dense with submerged macrophytes which decompose in the raining season. The substratum of the reservoir is mainly mud and sand [14].

Procedure for collection of fish specimens Samples were collected monthly from catches of local fishermen using traps, gill nets, and cast nets in the reservoir. Collection was done from November 2011 to October 2013, between 06:00 
- 08:00 am. Water from the reservoir was added to the samples at the point of collection before being transported to the research laboratory in the Department of Pure and Applied Biology, Ladoke Akintola University of Technology, Ogbomoso, Nigeria for further investigations. The first year, November 2011 to October 2012, called (2011/2012), 166 specimens (90 males; 76 females); the second year, November 2012 to October 2013, called (2012/2013), 162 specimens (96 males; 66 females) were studied.

\subsection{Species Identification}

Identification of Clarias gariepinus specimens was done using fish identification guides by [15] [16]. Sexes were identified using the description of [2]. The sexes were confirmed after dissection with the presence of testes in males and ovaries in females.

\subsection{Seasonal Studies}

During the period of investigation, rain was observed to fall from February to September, regarded as raining season while the months of October to January were regarded as dry season.

\subsection{Morphometric Studies}

\section{Sex Ratio}

The numbers of male and female sexes harvested in the fish species per year were counted and the ratio determined.

\section{The Length-weight relationship (LWR)}

The weight of each specimen was measured using a top loading Metler balance (model PN1200) to the nearest $0.1 \mathrm{~g}$ after draining excess water with a pile of filter paper, while total length (TL) were measured in centimeter $(\mathrm{cm})$ using a measuring board. Total length was used because no evidence of cannibalism was observed during the pre-data and data collection periods. The LWR was done using the description of [4]. Relationships of total length and body weight were examined by linear regression [17]. The length-weight regression equation was determined and the parameters a (regression constant), b (regression coefficient) and $\mathrm{R}^{2}$ (correlation coefficient) were estimated, using the SPSS version 15.0 for Windows.

\section{The condition factor " $K$ "}

The Condition factor (K value) was calculated as described by [18].

\subsection{Statistical Analysis}

Student $\mathrm{t}$ test at $\mathrm{p}=0.05$ was used to test for significant difference between the means of values obtained in seasons and between the two years of study. All statistical analyses were done using SPSS version 15.0 for Windows. Test for significance between the means of the $\mathrm{K}$ values of sexes in raining and dry seasons in each year, and between the means in the two years of study were done using in- 
dependent Student $t$ test at 95\% level of confidence.

\subsection{Examination for Parasites}

The fishes were sacrificed and examination for parasites, handling and processing followed standard procedure described by [19].

\subsection{Identification of Parasites to Species Level}

Fish specimens found with parasite were given separate serial numbers to differentiate them from those without parasites. Identifications were undertaken using information provided by [20] [21] [22] and confirmed with the assistance of [23] and [2], who had earlier confirmed the identity of the parasites through the assistance of the British Museum, United Kingdom.

\subsection{Processing of Recovered Parasites}

Cestodes and Nematode parasites recovered were stained using the procedure of [24]. Fixative used was Formalin acetic acid (FAA). Cestodes were stained using Acetocarmine; Nematodes were stained with Horen's trichome stain; while Acanthocephalans were stored in weak Erlich's haematoxylin solution overnight and dehydrated cleared in methyl-salicylate and mounted on a slide in Canada balsam.

\subsection{Statistical Analysis}

Parasitic infestations were tested using a non-parametric (Npar.) statistical method, (Kolmogorov-Smirnov K-S test) at 95\% level of confidence [14] using SPSS version 15.0 for Windows.

Significant difference between the means of the body weight; total length; of infested and uninfested fish specimens were carried out using the student $t$ test (2-tailed) at $95 \%$ level of confidence. A regression analysis was carried out on the length and weights of infested and uninfested fish specimens, the correlation coefficients $\mathrm{R}^{2}$ of good fit to the line of regression were determined.

\section{Results}

\subsection{Sex Ratio}

In the first year (2011/2012), a ratio of 1.18:1, (male: female) was recorded; in the second year (2012/2013), a ratio of 1.46:1 was recorded and in the two years combined, a ratio of 1.3:1 (male: female).

\subsection{Length-Weight Relationship}

Total length values of $C$. gariepinus in this study were an average of $28.53 \mathrm{~cm}$ (male) and $29.00 \mathrm{~cm}$ (female) for the two years; the body weights were $132.07 \pm$ $10.08 \mathrm{~g}$ in males and $141.00 \pm 9.40 \mathrm{~g}$ in females. The mean value for the total length and body weight of infested, uninfested and combined (i.e. when infested 
and uninfested fishes were not separated) of male and female fish is shown in Table 1. Regression analysis carried out between the length and weight of infested specimens and between the length and weight of uninfested specimens, all showed positive linear relationships (Table 2).

\subsection{The Condition Factor (K)}

The condition factor values $(\mathrm{K})$ for combined, infested, and uninfested fish in both sexes of the two years were shown in Table 1 . The $\mathrm{K}$ values for the length size distribution for combined sexes were shown in Figure 1.

Seasonal distribution of Clarias gariepinus in Oba reservoir.

More fish specimens were caught in the dry season (194) than the raining season (134).

\subsection{Anthropological Activities}

Poultry and Piggery farms located in the surroundings of the reservoir were observed to be discharging their wastes into rivers serving as tributaries to the reservoir. Also observed were different crop farming and irrigation activities around the reservoir.

\subsection{Enteroparasites Recovered}

Parasites recovered were comprised of two Nematodes Procamallanus laevionchus (Wedl, 1862), Paracamallanus cyathopharynx (Baylis, 1923), three Cestodes Anomotaenia sp., Monobothrium sp., Polyonchobothrium clariae, and one Acanthocephalan, Neoechinorhynchus rutili (Mueller, 1780).

\subsection{Parasite Prevalence}

The prevalence was $30.12 \%$ in females and $24.10 \%$ in males in $2011 / 2012$; in $2012 / 2013$ it was $30.86 \%$ and $16.05 \%$ respectively. Generally it was higher in $2011 / 2012(54.22 \%)$ than in $2012 / 2013(46.91 \%)$ and in the two years it was $50.57 \%$.

Seasonally, prevalence was $65.96 \%$ in the dry season and $38.89 \%$ in the raining season of 2011/2012; in 2012/2013, it was $52.08 \%$ and $39.39 \%$ respectively.

Table 1. Means of Morphometric parameters of Clarias gariepinus from Oba reservoir.

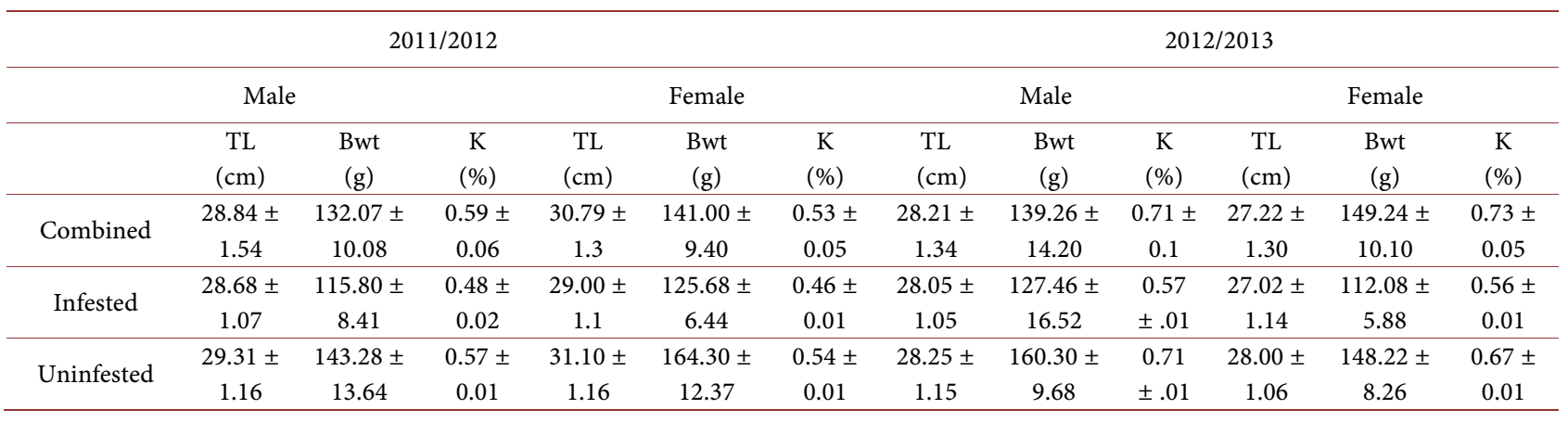

Combined means infested and uninfested fish; $\mathrm{TL}=$ total length; $\mathrm{Bwt}=$ body weight; $\mathrm{K}=$ condition factor. 
Table 2. Length-weight regression values of Clarias gariepinus in Oba reservoir.

\begin{tabular}{|c|c|c|c|c|c|c|c|c|}
\hline \multicolumn{5}{|c|}{$2011 / 2012$} & \multicolumn{4}{|c|}{$2012 / 2013$} \\
\hline & \multicolumn{2}{|c|}{ Male } & \multicolumn{2}{|c|}{ Female } & \multicolumn{2}{|c|}{ Male } & \multicolumn{2}{|c|}{ Female } \\
\hline & “b” & $\mathrm{R}^{2}$ & "b" & $\mathrm{R}^{2}$ & "b" & $\mathrm{R}^{2}$ & "b" & $\mathrm{R}^{2}$ \\
\hline Combined & 3.442 & 0.869 & 3.133 & 0.518 & 3.913 & 0.880 & 3.506 & 0.701 \\
\hline Infested & 2.875 & 0.778 & 2.826 & 0.198 & 2.913 & 0.781 & 2.395 & 0.482 \\
\hline Uninfested & 3.995 & 0.995 & 3.437 & 0.839 & 4.915 & 0.915 & 4.617 & 0.920 \\
\hline
\end{tabular}

Combined means infested and uninfested fish; Regression coefficient $=$ ("b”) and correlation coefficient $=\left(R^{2}\right)$.

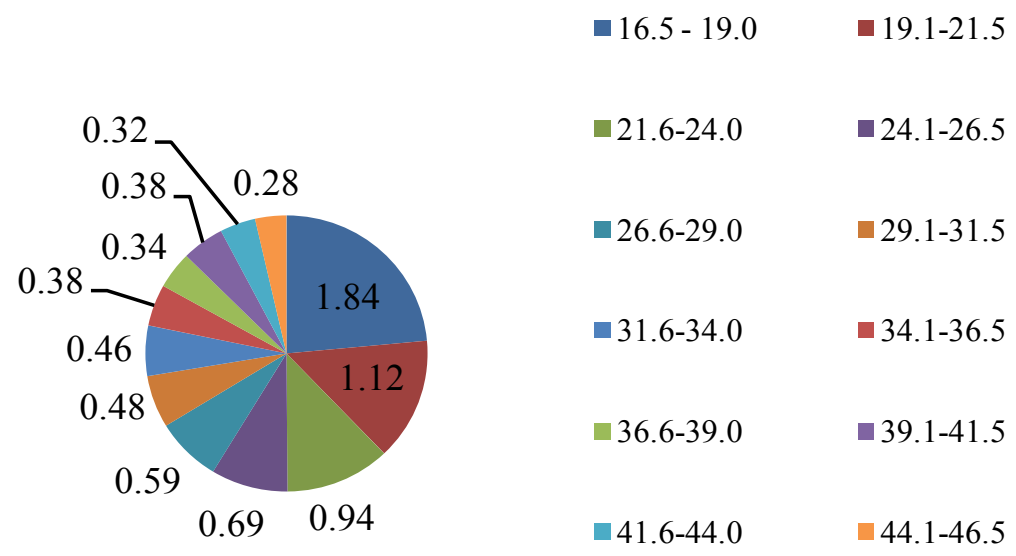

Figure 1. Condition factor of different length $(\mathrm{cm})$ groups for combined sexes of Clarias gariepinus in Oba reservoir.

\subsection{Statistical Tests}

Kolmogorov-Smirnov Z (KSZ) test at $\mathrm{p}=0.05$ between the means of parasitemia in fish specimens of 2011/2012 and 2012/2013 was not significant $(p=0.071)$.

A test at $\mathrm{p}=0.05$ between means of parasitemia in male $(46.06 \pm 3.61)$ and female mean of $67.81 \pm 8.93$ in 2011/2012 was not significant $(p=0.061)$.

A test at $\mathrm{p}=0.05$ between means of parasitemia in male $(22.75 \pm 2.53)$ and female mean of $87.77 \pm 8.19$ in 2012/2013 was significant ( $p=0.041$ ).

\subsection{Parasite Intensity}

The intensity of all parasite species was higher in females than males in the two years. A regression between parasite intensity and body weight of infested fish in the two years showed that the relationships were negatively correlated.

In $2011 / 2012$, the regression equation was $y=-0.383 \times 90.88 ; R^{2}=0.147$; in $2012 / 2013$, the equation was $y=-0.321 \times 81.69 ; R^{2}=0.184$.

\section{Discussion}

The result of sex ratio showed that both sexes were available in the reservoir with males more than females with a ratio of 1.3:1, male to female. The high number of captured males over females could be due to the fact that once the eggs were 
fertilized by the males, the males migrate to the feeding zones where they become vulnerable to capture, while the females on the other hand remain in hiding under vegetation where incubation of eggs took place. [25] [26] were of the opinion that the possibility of not getting gears closer to the breeding grounds may also increase the chances of the female not getting caught. [7] Reported a sex ratio of 1:1 for C. gariepinus in Oba reservoir. Similar observations have also been established in the population of other cat fishes in some Nigerian water bodies by [27]. [28] attributed this disparity to different survival mechanisms over certain environmental conditions. The female fish specimens caught had a higher total length and body weight than the male (Table 1), this may be due to matured female fish having heavier gonads due to presence of eggs, and space is required to accommodate the eggs. Seasonally, more fish were caught in the dry seasons than the raining seasons. The low percentage of fish caught in the raining season could be as a result of high volume of water in the reservoir and $C$. gariepinus being a benthic species, will be difficult for fishermen using cast netting, gill netting and traps to catch due to accessibility to the bottom of the reservoir where the fish species mostly found. The high water level will also be a hindrance as most fishermen would not go fishing when the water level was high.

The length-weight relationship of the fish in Oba reservoir showed a positive linear relationship indicating that an increase in length leads to an increase in weight. The regression coefficient " $b$ " recorded for male and female specimens (when infested and uninfested were not separated) were higher than 3 (Table 2). This indicated that males and females exhibited positive allometric growth. In fishes which maintain dimensional equality, the isometric value will be 3 [29], regression coefficient " $b$ " larger (positive) or smaller (negative) than 3.0 shows an allometric growth [30]. A positive allometric growth means the fish body weight increases faster than the length increases. The male result conformed to the findings of [31] who reported a " $b$ " value of 7.74 for males, but the result contradicted that of [8] who obtained a "b" value of 2.485 for males in Oba reservoir. The result obtained was in agreement with the findings of [32] who reported that the "b" value of male C. gariepinus was higher than that of females though females also exhibited a positive allometric growth. However, the " $b$ " values for infested fishes of both sexes in the two years were less than 3 , indicating negative allometric growth, which showed the fish grew faster in length than the weight, an indication that the infestation had probably affected the growth in weight.

The " $\mathrm{b}$ " value could be an indicator of the physiological condition of the fish and it varies seasonally in response to seasonal variations in environmental condition and changes in the fish wellbeing [33]. The length-weight relationship and the " $b$ " value can also be influenced by fishing pressure that excessively crops the adults [34]. The correlation coefficient $\left(R^{2}\right)$ for male and female in 2011/2012 showed that the values for female were low and not in good fit to the line of re- 
gression as that of males (Table 2). Differential feeding habit, scarcity of food, parasitic infestation, and/or infection among others could be responsible. However, the role of enteroparasites in the life of $C$. gariepinus was found to probably be a major factor responsible for the low percentage of good fit to the line of regression in females. The correlation coefficient $\left(R^{2}\right)$ values in 2012/2013 for male and female sex indicated good correlation though lower in female. This was in agreement with the reports of [7] who reported 0.7349 and 0.8544 for males and females respectively and [32] who also reported high percentage of good fit to the line of regression for $C$. gariepinus.

The mean condition factor $(\mathrm{K})$ values recorded for males was higher than female in the first year and the values were significantly different at $p=0.05$. In the second year, the values showed no significant difference; which indicated that generally males lived in good condition and their general well-being was better than the female fish in the reservoir. This could be because females expend a lot of metabolic energy that could have been used for body building in spawning activities. This is in agreement with the findings of [7] who reported 1.48 and 0.98 for male and female $C$. gariepinus respectively from Oba reservoir in Ogbomoso. The $\mathrm{K}$ values in the small sized fish specimens in the two years of study were high and it decreased progressively as the size gets larger (Figure 1). This suggests that the relatively smaller sized fishes are better adapted to the ecological conditions of the reservoir. [35] attributed the decline in $\mathrm{K}$ values to the deposition of materials for gonad formation, which may lead to increase in weight and actual spawning which lead to reduction in fish weight respectively.

Species diversity of parasites in the enteron of C. gariepinus in Oba reservoir was high. This may be as a result of anthropological activities around the reservoir, such as discharge of animal wastes into rivers feeding the reservoir. Seasonal variation showed higher prevalence of parasite infestation in the dry season than the raining season in the two years. The result obtained may be due to eutrophication, which often raises parasitism because the associated increase in productivity will increase the abundance of the invertebrates which serve as intermediate hosts to the piscine parasites that were mostly fresh water insects and crustaceans. This probably brings the maturity of the parasites in the fish that fed on the infected invertebrates towards the dry season, depending on the life cycle of individual parasite. Another factor may be a drop in water level in the dry season exposing the invertebrates to their fish predators. Prevalence was found to be higher in females than males in the two years of study and it was higher in $2011 / 2012$ with $54.22 \%$ than in 2012/2013 with $46.91 \%$. This showed that female C. gariepinus were more susceptible to parasitic infestation than males. This was also supported by the intensity of parasitemia, which showed that the intensity of all the parasites were higher in females than in males in the two years of study. This may be as a result of differential in feeding, either by quantity or quality of food eaten, or as a result of different degree of resistance to infestation [36] [37] were of the opinion that due to the physiological state of the female, 
most gravid females could have reduced resistance to infection and infestation by parasites. The result was in consonance with the work of authors like [38] who reported an intensity of 2.67 in females and 1.43 in males of $C$. gariepinus from Ilorin Nigeria; [10] reported significant difference at $p=0.05$ in the infestation of C. gariepinus male with $48.78 \%$ and female with $51.22 \%$ from Oba reservoir; [11] also reported significant difference at $\mathrm{p}=0.05$ between male with $43.80 \%$ and female with $56.20 \%$ of $C$. gariepinus from Erinle reservoir in Osun state.

The student $t$ tests between the body weights of infested and uninfested females in the two years were significant at $p=0.05$, while those of males were not significant. This indicated that parasitic infestation of $C$ gariepinus in Oba reservoir had a greater effect on the weight of the female fish than it had on the male fish. A regression analysis between parasite intensity and body weight in infested fish for the two years were negatively correlated. This showed that as the intensity of parasite increases the body weight reduces and vice versa. The condition factor recorded for males were higher than the ones recorded for female in the two years; probably because the males were less infested. This is in consonance with the findings of [23] that parasitized male C. gariepinus had a lower condition factor than un-parasitized ones in Zaria. It was also reported that the condition factor reduces as the body size increases; though infestation and body size were not investigated, report from other authors showed that adults (large size) C. gariepinus from were mostly infested followed by sub adults and juveniles [7].

\section{Conclusion}

Parasitic infestation of C. gariepinus by Procamallanus laevionchus, Paracamallanus cyathopharynx, Anomotaenia sp. Monobothrium sp., Polyonchobothrium clariae and Neoechinorhynchus rutili in Oba reservoir was found to reduce the growth in weight of the fish. This reduction led to a decrease in the value of regression coefficient, giving the infested fishes a negative allometric growth pattern. The effect of the parasitic infestation on the weight affected the values of morphometric indices. Prevalence and intensity are higher in females than males, and also higher in dry than in raining season. High enteroparasitic infestation can greatly reduce the productivity of fish in aquaculture. It is suggested that anthropological activities around Oba reservoir be monitored in order to maintain a healthy aquatic environment and protect the resident fish species.

\section{Conflicts of Interest}

The authors declare no conflicts of interest regarding the publication of this paper.

\section{References}

[1] Adesulu, E.A and Sydenham, D.H.J. (2007) The Freshwater Fishes and Fisheries of Nigeria. Macmillan Nigeria Publishers Ltd., Nigeria, 397 p. 
[2] Akinsanya, B. and Otubanjo, O.A. (2006) Helminth Parasites of Clarias gariepinus (Clariidae) in Lekki Lagoon, Lagos, Nigeria. Revista de Biologia Tropical, 54, 93-99. https://doi.org/10.15517/rbt.v54i1.14003

[3] Froese, R. (2006) Cube Law, Condition Factor and Weight-Length Relationships: History, Meta-Analysis and Recommendations. Journal of Applied Ichthyology, 22, 241-253. https://doi.org/10.1111/j.1439-0426.2006.00805.x

[4] Froese, R. and Pauly, D. (2011) FishBase. World Wide Web Electronic Publication. http://:www.fishbase.org

[5] Bagenal, T. (1978) Method for Assessment of Fish Production in Fresh Waters. Third Edition, IBP Handbook No 3, Blackwell Scientific Publication, Oxford, 365 p.

[6] Anyanwu, P.E., Okoro, B.C., Anyanwu, A.O., Matanmi, M.A., Ebonwu, B.I., Ayaobu-Cookey, I.K., Hamzat, M.B., Ihimekpen, F. and Afolabi, S.E. (2007) LengthWeight Relationship, Condition Factor and Sex Ratio of African Mudcatfish (Clarias gariepinus) Reared in Indoor Water Recirculation System Tanks. Research Journal of Biological Sciences, 2, 780-783.

[7] Fawole, O.O. and Adewoye, S.O. (2004) Aspect of the Biology of Clarias gariepinus (BURCHELL, 1822) in Oba Reservoir, Ogbomoso, Nigeria. Science Focus, 8, 96-100.

[8] Roberts, L.S. and Janovy, J. (2000) Gerald D. Schmidt and Larry S. Robert's Foundations of Parasitology. 6th Editions, McGraw-Hill International, Boston, MA.

[9] van Rensburg, C.J., van As, J.G. and King, P.H. (2013) New Records of Digenean Parasites of Clarias gariepinus (Pisces: Clariidae) from the Okavango Delta, Botswana, with Description of Thaparotrema botswanensis sp.n. (Plathelminthes: Trematoda). African Invertebrates, 54, 431-446. https://doi.org/10.5733/afin.054.0210

[10] Ajala, O.O. and Fawole, O.O. (2014) Multiple Infections of Helminths in the Stomach and Intestine of Clarias gariepinus (Burchell, 1822) in Oba Reservoir, Oyo State, Nigeria. IOSR Journal of Pharmacy and Biological Sciences, 9, 5-12. https://doi.org/10.9790/3008-09350512

[11] Ajala, O.O. and Fawole, O.O. (2014) Multiple Infections of Helminths in the Alimentary System of Clarias gariepinus (Burchell, 1822) in a Tropical Reservoir. International Journal of Fisheries and Aquaculture, 6, 62-70. https://doi.org/10.5897/IJFA2014.0417

[12] Food and Agriculture Organization/WHO (2014) Multicriteria Based Ranking for Risk Management of Foodborne Parasites. Report of a Joint FAO/WHO Expert Meeting, Rome, 3-7 September 2012.

[13] Paperna, I. (1996) Parasites, Infections and Diseases of Fishes in Africa: An Update. CIFA Technical Paper, 31, 157-170.

[14] Ajala, O.O. (2015) Studies on Aspects of Limnology and Biology of Selected Fish Species in Oba Reservoir, Ogbomoso, Nigeria. Ladoke Akintola University of Technology, Ogbomoso, Nigeria.

[15] Food and Agriculture Organization (1992) Field Guide to the Freshwater Fishes of Tanzania. Food and Agricultural Organization, Rome, 145.

[16] Olaosebikan, B.D. and Raji, A. (1998) Field Guide to the Nigerian Fresh Water Fishes. Federal College of Freshwater Fisheries Technology, New Bussa, Nigeria.

[17] Hossain, M.Y., Ahmed, Z.F., Leunda, P.M., Islam, A.K.M.R., Jasmine, S., Oscoz, J., Miranda, R. and Ohtomi, J. (2006) Length-Weight and Length-Length Relationships of Some Small Indigenous Fish Species from the Mathabhanga River, Southwestern BANGLADESH. Journal of Applied Ichthyology, 22, 301-303. https://doi.org/10.1111/j.1439-0426.2006.00801.x 
[18] Tesch, W. (1971) Age and Growth. In: Ricker, W.E., Ed., Methods for Assessments of Fish Production in Freshwaters, International Biological Programme, Oxford, 97-130.

[19] Moravec, F. (2004) Some Aspects of the Taxonomy and Biology of Dracunculoid Nematodes Parasitic in Fishes: A Review. Folia Parasitologica, 51, 1-13.

[20] Yamaguti, S., (1963) Systema Helminthum. The Acanthocephalans. Inter Science Publishers, Inc. New York.

[21] Ukoli, F.M.A. (1969) Preliminary Report on the Helminthic Infections in the River Niger at Shagunu (Near Kainji). In: Obeng, L., Ed., Proceedings of the Accra Symposium, Man-Made Lakes, Accra, November 21-24, 1966, 269-283.

[22] Kabata, Z. (1985) Parasites and Diseases of Fish Culture in the Tropics. Taylor Francis, London, 107.

[23] Oniye, S.J., Adebote, D.A. and Ayanda, O.I. (2004) Helminthes Parasites of Clarias gariepinus (Tuegels) in Zaria, Nigeria. Journal of Aquatic Sciences, 19, 71-75. https://doi.org/10.4314/jas.v19i2.20027

[24] Khalil, L.F. (1991) Techniques for Identification and Investigative Helminthology. Helminthology Manual. International Institute of Parasitology, St. Albans, UK, 156.

[25] Olele, N.F. (2010) Reproductive Biology of Sarotherodon galilaeus (Artedi, 1757) in Onah Lake, Delta State, Nigeria. Journal of Applied Sciences Research, 6, 1981-1987.

[26] Guclu, S.S. and Kucuk, F. (2011) Reproductive Biology of Aphanius mento (Heckel in: Russegger, 1843) (Osteichtyes: Cyprinodontidae) in Kirkgoz Spring (Turkey). Turkish Journal of Fisheries and Aquatic Sciences, 11, 323-327.

[27] Abayomi, O.S. and Arawomo, G.A.O. (1996) Sex Ratio and Fecundity of C. Gariepinus in Opa Reservoir, Ile-Ife, Nigeria. Proceedings of the Annual Conference of the Fisheries Society of Nigeria, New Bussa, Nigeria, 3-8 November 1996, 122-130.

[28] Ham, R. (1981) The Ecology of Six Native and Two Introduced Fish Species in Enoggere Creek System, South East, Queens Land. Griffith Universidad, Brisbane, Australia.

[29] Offem, B.O., Samsons, Y.A. and Isaac, T.O. (2009) Length-Weight Relationship, Condition Factor and Sex Ratio of Forty Six Important Fishes in a Tropical Flood River. Research Journal of Fisheries and Hydrobiology, 4, 65-72.

[30] Bagenal, T.B. and Tesch, F.W. (1978) Age and Growth of Fish in Methods for Assessment of Fish Production in Freshwaters. Blackwell Scientific Publication. Oxford, London, $365 \mathrm{p}$.

[31] Davies, O.A., Tawari, C.C. and Keme-Iderikumo, K. (2013) Length-Weight Relationship, Condition Factor and Sex Ratio of Clarias gariepinus Juveniles Reared in Concrete Tanks. International Journal of Scientific Research in Environmental Sciences, 1, 324-329. https://doi.org/10.12983/ijsres-2013-p324-329

[32] David, D.L., Edward, A., Adass, P.A. and Jesse, C. (2010) Some Aspects of Water Quality and the Biology of Clarias gariepinus in Vimtim Stream, Mubi Adamawa State, Nigeria. World Journal of Fish and Marine Sciences, 2, 129-133.

[33] Biswas, A. (1993) Management of International Waters: Problems and Perspective. Water Resources Development, 9, 142-145. https://doi.org/10.1080/07900629308722582

[34] Okogwu, I.O. (2011) Age, Growth and Mortality of Clarias gariepinus (Siluriformes: Clariidae) in the Mid-Cross River-Floodplain Ecosystem, Nigeria. Revista de Biología Tropical, 59, 115-119. https://doi.org/10.15517/rbt.v59i4.3433 
[35] Mgbenka, B.O. and Eyo, J.E. (1992) Aspects of the Biology of Clarias gariepinus Anambra River Basin 2: Maturation and Condition Factor. Journal of Agricultural Science and Technology, 2, 52-55.

[36] Emere, M.C. (2000) Parasitic Infection of the Nile Perch Lates niloticus (L) in River Kaduna. Journal of Aquatic Sciences, 15, 51-54.

https://doi.org/10.4314/jas.v15i1.19988

[37] Emere, M.C. and Egbe, N.E.L. (2006) Protozoan Parasites of Synodontis clarias (A Fresh Water Fish) in River Kaduna. The Best Journal, 3, 58-64.

[38] Ayanda, O.I. (2009) Comparison of Parasitic Helminthes Infection between the Sexes of Clarias gariepinus from Asa Dam Ilorin, North-Central, Nigeria. Scientific Research and Essay, 4, 357-360. 